\title{
Research on Social Security Management Based on Intelligence Policing In the Context of Dig Data
}

\author{
Yue Qingchun ${ }^{1, *}$ \\ ${ }^{1}$ China People's Police University. Langfang, Hebei, 065000, China
}

\begin{abstract}
Under the strategic background to strengthen the police with science and technology, intelligence policing is a new model formed by public security organs based on the integration, fusion and application of big data, which provides system support and technical guarantee for the current social security management work. This article focuses on social security management in the context of intelligence policing, and systematically analyzes the specific practice and inherent characteristics of the construction of intelligence policing, then to build a scientific and reasonable social safety management mechanism. This not only has important theoretical significance, but also has certain practical value to comprehensively improve police efficiency and enhance social governance capabilities.
\end{abstract}

\section{Introduction}

The rapid development of a new generation of information technology such as big data and cloud computing gave birth to the "Internet +" era, intelligence policing based on the development of a new generation of information technology has also emerged.

At present, as an the strategy to strengthen the police with science and technology, which is a new type of policing concept spawned by the police revolution. Social security management based on intelligence policing gradually becomes an important engine to improve police efficiency and innovate police models. Specifically, intelligence policing is the comprehensive integration of digitization, intelligence and networking of the police system. Various functional modules are implemented through advanced hardware platforms and software systems. In turn, it can respond to various types of police services in a timely and efficient manner, and achieve the purpose of "high integration, system sharing, and in-depth application". In the social security management work, we should rely on the network platform, based on information collection, taking system prevention and control as the guidance, then to build a sustainable and efficient social security management mechanism. We may take information collection, resource sharing, collaborative response, and intelligent prevention and control as the focus of social security management to strengthen the monitoring and early warning functions, system prevention and control functions under the vision of intelligence policing.

Intelligence policing is a new model created by public security organs based on the integration, fusion and application of big data under the background of the information age. ${ }^{[1]}$ Social security management based on intelligence policing has three meanings. Firstly, it can help us to improve the theoretical system of intelligence policing, and grasp the focus and direction of policing construction, which can promote the in-depth development of intelligence policing with a systematic theoretical system. Secondly, it helps to build a data platform for intelligence policing, and then gathers information and data scattered in various fields, levels, and types of police into a unified data exchange center, so that social security prevention and control capabilities can be more effectively improved. Finally, it can improve the governance efficiency of intelligence policing, which will solve the contradiction between the vertical division of labor and the horizontal demand integration, then to realize the optimal allocation of police resources.

\section{Specific application}

\subsection{Foreign applications}

Since the 1990s, with the rapid development of information technology, the world's fourth police revolution has bred. At present, policing in the world has fully entered the era of intelligence policing. The research on social security management based on intelligence policing in western developed countries started earlier. Especially in recent years, related research fields have continued to expand, and the technical level has been continuously improved. The following is a systematic analysis from three typical countries. Firstly, American model. As an emerging paradigm of American police work in recent years, the relevant research is reflected in five aspects: locally driven, emphasizing the dominant position of the local police department in social security management; scientific research, emphasizing the

\footnotetext{
* Corresponding author: yueqingchun@ $163 . c 0 m$
} 
evaluation and design of experiments or quasiexperiments; multidimensional measures, public security issues based on comprehensive analysis often require dynamic multidimensional intervention measures; resultoriented, taking effective evaluation as a test of intelligence policing; system innovation, law enforcement agencies continue to develop and test new social security management methods or new applications of existing methods. ${ }^{[2]}$ Secondly, British model. In order to solve the problem of the low level of information coordination among police departments in different regions, the United Kingdom established the national crime intelligence agency. England, Scotland and Wales established a unified security intelligence system to collect, monitor, research and share intelligence. After the application of this model, the crime rate in the UK has continued to decline and the public security situation has improved significantly. Thirdly, Australian model. Through the construction of a "national team" model, the police agency's ability to collect and process information has been strengthened. Based on the police agency's monitoring and early warning, it has coordinated with other government agencies' information resources, and the police agency will lead the establishment of a comprehensive national level. The database makes the system data more timely and comprehensive, so as to better serve the information application of the police agency's public security management.

\subsection{Domestic applications}

Domestic theoretical research on the construction of intelligence policing has a relatively short period of time, and is still in a new stage, the development of practice is faster than theoretical research, which is obviously ahead ${ }^{[3]}$ In order to meet the needs of the construction of intelligence policing, public security agencies in various places have carried out a lot of explorations on the construction of intelligence policing, and have effectively connected big data, cloud storage, cloud computing, Internet of things and other technological tools with social security management work, then forming distinctive police service mode. One is the Jinan model. Based on the "policing cloud" application system, through the construction of a police information sharing database, connects the province's public security system with crossregional, cross-departmental, and cross-police data sharing and coordinated operations. At present, the city's public security cloud computing center has formed one data center, four networks (public security intranet, Internet, image private network, secure access network), five platforms (storage platform, network platform, management platform, application platform, security platform) have been established. The second is the Shenzhen model. Shenzhen public security organs implement the strategy of strengthening the police through science and technology, and apply intelligence policing to the management of social security. On the one hand, the use of information technology to promote the "flattening" of public security organizations has solved the problem of internal attrition of police force caused by excessive division of labor and unclear responsibilities in the process of social security management. On the other hand, with the help of big data, cloud computing, Internet and other technologies to reshape the police process, break the organizational boundaries, optimize public security organizations and police processes, and actively explore the reform of the police system and mechanism. The third is the Fujian model. Relying on Tencent's big data, cloud computing and other scientific and technological tools, the public security organs of Fujian Province have created a modern police service model, improved the level of police information, and resolved bottlenecks such as single service methods and information release blockages in social security management.

\section{Basic characteristics of intelligence policing}

Social security management from the perspective of intelligence policing is based on the traditional social security prevention and control system, giving full play to the engine and supporting role of big data in modern policing. Thereby, forming a more complete and effective social security prevention and control system with faster information, more sensitive intelligence, more comprehensive data, faster response, more effective control, and more precise strikes, it has three characteristics.

\subsection{Integrity}

The creation of the intelligence policing model not only maintains the overall functions of the social security prevention and control system, but also further strengthens the relationship between prevention and control subjects through the application of big data. It combines the previously independent and decentralized prevention and control forces, as well as all available social security resources, in accordance with the principle of system optimization to build a low internal consumption, reasonable coordination and complementary social prevention and control system, which greatly improves the public security organs.

\subsection{Diversity}

Social security management is a dimensional system with three vertical levels(As shown in Figure 1). The first is the basic layer, which is the main prevention and control layer composed of community prevention and control, position prevention and control, and unit internal prevention and control. The second is the middle layer, which is based on the "110" command center, taking various police types as the main body of the public security organs, relying on the power of group defense and group governance, then to form full-time and space inspection and control as the basic service method, which can build a prevention and control layer with a rapid response mechanism as the guarantee. The third is the target layer, which is information-oriented, and mainly aims at organized crimes, drug crimes, terrorist crimes, serious violent 
crimes, multiple sexual crimes, economic crimes, and high-tech crimes, thereby forming the criminal investigation prevention and control layer. The three levels have clear subjects, clear functions, meticulous prevention and control, forming an organic

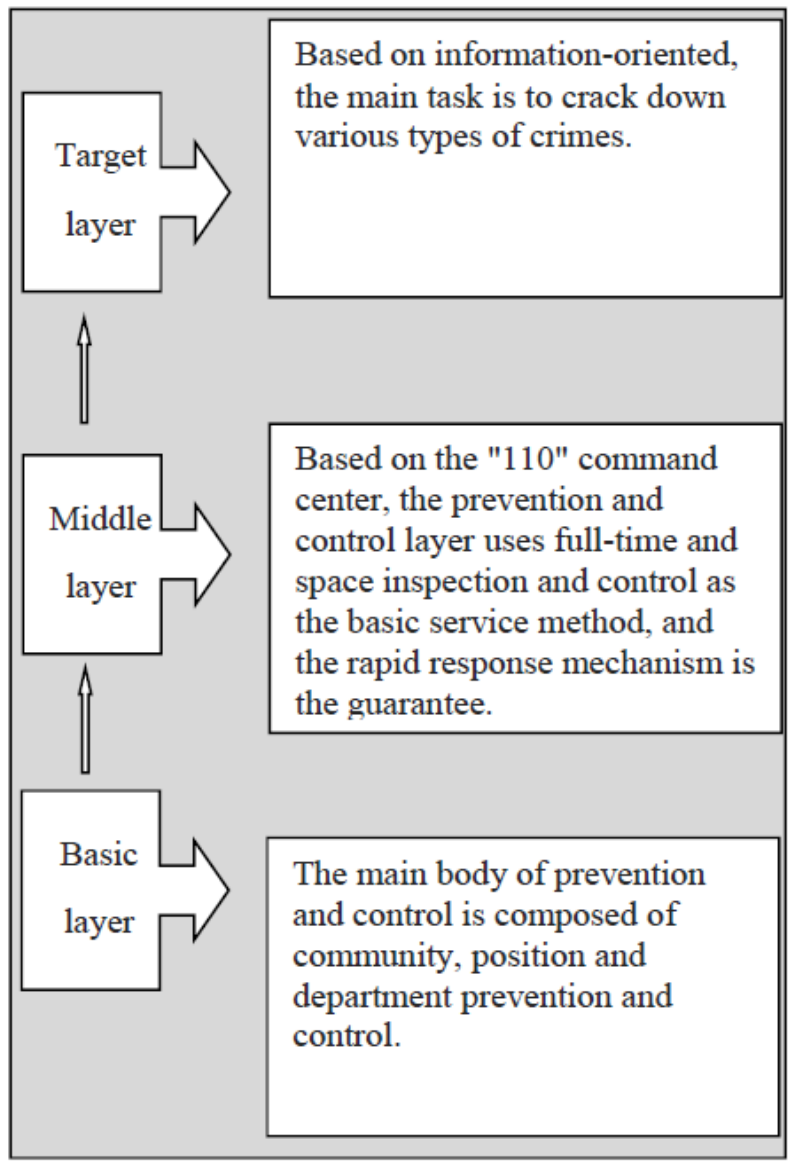

Fig. 1. Basic characteristics of intelligence policing.

\subsection{Versatility}

Social security management is a multi-functional system, and its inherent structure determines the functionality of system. At present, public security organs must have new ideas and new strategies in the face of complex public security situations. The system of social security management is a complex system that integrates various prevention and control elements. Because the three levels in the vertical structure of the social security prevention and control system are connected and interrelated, forming an organic and unified system, which has the functions of attack, prevention, control, management. At the same time, various functions are playing an active role as part of the overall functions of the prevention and control system.

\section{Social security management countermeasures based on intelligence policing}

Social security management based on intelligence policing is a complex system with multiple levels, and various factors show a certain level of relationship, forming a more complex system chain. Specifically, based on the current theoretical research and practical process, according to the structural dimension, process dimension and goal dimension research paradigm, it mainly covers the system level, the object level, the mechanism level and the information level (As shown in Table 1).

Table 1. Countermeasures to construct intelligence policing.

\begin{tabular}{|c|c|c|}
\hline $\begin{array}{c}\text { Structure } \\
\text { Dimension }\end{array}$ & $\begin{array}{c}\text { Process } \\
\text { Dimension } \\
\end{array}$ & $\begin{array}{c}\text { Goal } \\
\text { Dimension }\end{array}$ \\
\hline System Level & $\begin{array}{l}\text { Network architecture, } \\
\text { Business architecture, } \\
\text { Application architecture }\end{array}$ & $\begin{array}{l}\text { Overall } \\
\text { system }\end{array}$ \\
\hline Object Level & $\begin{array}{c}\text { Key places } \\
\text { Key objects } \\
\text { Prevention and control } \\
\text { Systems }\end{array}$ & $\begin{array}{c}\text { Overall } \\
\text { orientation }\end{array}$ \\
\hline $\begin{array}{c}\text { Mechanism } \\
\text { Level }\end{array}$ & $\begin{array}{l}\text { Real-time monitoring } \\
\text { Dynamic management } \\
\text { Information sharing } \\
\text { Resource allocation }\end{array}$ & $\begin{array}{l}\text { Overall } \\
\text { process }\end{array}$ \\
\hline $\begin{array}{l}\text { Information } \\
\text { level }\end{array}$ & $\begin{array}{l}\text { Network supervision } \\
\text { Remote monitoring } \\
\text { Intelligence emergency }\end{array}$ & $\begin{array}{l}\text { Overall } \\
\text { platform }\end{array}$ \\
\hline
\end{tabular}

\subsection{System level}

Intelligence policing should be based on the social security management framework to achieve system-wide coverage. First of all, the system should be based on the Internet, and its system technical architecture should be consistent with the classic structure of the network, including the perception layer, network layer, processing layer, and application layer from top to bottom. Secondly, the business structure of the system is mainly based on the needs of "prevention" and "control". Its basic logic should fully embody "police-led, public participation, and information support", and then establish a linkage structure that organically combines "prevention", "control", and "group". ${ }^{[4]}$ Finally, this system should build five application subsystems based on the needs of social security management, specifically including "intelligence monitoring system", "intelligence early warning system", "intelligence dispatch system", "intelligence guarantee system" and "intelligence service system". The system is not only a component of the "intelligence policing" system, but also the core of social security management. 


\subsection{Object level}

Intelligence policing should achieve comprehensive coverage based on the object of social security management. Specifically, it includes three dimensions. The first is key places, which mainly rely on police resources to ensure the efficiency of the prevention and control process. The second is the key objects, it aims to strengthen the monitoring capabilities of key protected objects, the comprehensiveness of the prevention and control process is ensured. The third is the prevention and control system, which uses the monitoring and early warning of system to ensure the timeliness of the prevention and control process.

\subsection{Mechanism level}

Intelligence policing should be based on social security management mechanisms to achieve full process coverage. Firstly, a real-time monitoring mechanism, with the help of Internet technology, the monitoring systems of various units are connected to realize process monitoring. Secondly, a dynamic management mechanism, which uses hardware facilities and software technology to share information with the Internet in a timely and on-the-spot connection, then provide the efficiency and effectiveness of social security management. Thirdly, a information sharing mechanism, taking advantage of the opportunities in the construction of "intelligence cities" in various places, it can establish a dynamic and efficient big data center, and realize the interconnection of various government departments, and then build an information database and a grid management platform. Finally, a resource allocation mechanism, we should use information technology to achieve comprehensive assessment, which may provide scientific guidance for weak links and management blind spots in various safety work, and to rationally allocate various police resources according to urban planning and layout.

\subsection{Information level}

Intelligence policing should achieve full platform coverage based on social security management information. Firstly, building a safety supervision platform. The components of the safety supervision platform cover front-end networking equipment, alarm monitoring network, monitoring center system, etc. Through this system, you can timely and accurately grasp the specific conditions of equipment operation, public security situation, personnel inspection, etc. Secondly, building a remote monitoring platform for cities. Monitoring and early warning is the outpost of emergency management. ${ }^{[5]}$ Through the communication network and the remote monitoring system, the automatic alarm system can be connected, and the monitoring of the units in the jurisdiction can be realized in the way of real-time video. Finally, building a "smart emergency" platform. The basic support of the so-called "smart emergency" platform is a new type of information technology that comprehensively applies the Internet, data fusion, cloud computing, etc., then to realize the data collection, storage, analysis and other links.

\section{Conclusion}

Based on the theory and practice of intelligence policing, this article systematically analyzes the specific applications of intelligence policing at home and abroad, and then puts forward relevant policy recommendations from the system level, object level, mechanism level, and information level, which can provide theoretical reference for safety management work.

\section{Acknowledgments}

The Project of Research and Innovation for Young and Middle-aged Teachers in China People's Police University: Research on Social Security Management Mechanism Based on "Intelligence Policing"(No.ZQN2021012)

The Soft Science Project of Langfang City: Research on Social Fire Safety Management from the Perspective of "Intelligence Fire Protection"(2020029004)

\section{References}

1. Zhou Jingru.(2018)Reflection on the Social Public Security Prevention and Control System Construction in the Vision of Intelligence Policing. Journal of Police Science Research, Changchun.

2. Zhu Xiaobo.(2018)Study on the Police Intelligent Information System of America. Journal of Shanghai Police College, Shanghai.

3. Zhang Qian.(2019)A Brief Analysis on the Problems to be Solved Urgently in the Construction of Intelligent Policing and its Countermeasures. Journal of Beijing Police College, Beijing.

4. Research Group on Smart Policing of Shanghai Police College.(2018)Background, Systematic Structure and Ways of Developing Smart Fire Prevention. Journal of Shanghai Police College, Shanghai.

5. Yue Qingchun.(2018)Research on Emergency Management Mechanism in China. University of Electronic Science and Technology Press, Chengdu. 